\title{
CORRECTIONS TO "SPEED OF CONVERGENCE IN NONPARAMETRIC KERNEL ESTIMATION OF A REGRESSION FUNCTION AND ITS DERIVATIVES"
}

\author{
AleXANDER A. GeORGIEV \\ Scientific and Engineering Services, Research and Development Department, \\ Ethyl Corporation, P.O. Box 14799, Baton Rouge, LA 70898, U.S.A.
}

In the above titled paper (this Annals Vol. 36, No. 3, A (1984), pp. 455-462), we wish to correct eight errors, whose presence can make the reading of the paper somewhat difficult.

a) In Section 1, p. 455, the first sentence should read: The nonparametric regression problem is that of estimating the expectation $g(x)=E(Y ; x)$, where $x$ is an observed non-random point.

b) In Section 1, p. 456, the definitions should read:

(i) $A_{i}=\left\{x: x_{i-1}<x \leq x_{i}\right\}, A=U A_{i}, i=1,2, \ldots, n$,

(iii) $\|f\|=\sup _{0<x<1}|f(x)|,\||f|\|=\sup _{x \in A}|f(x)|$,

(v) " $x_{i}^{n} \in O D$ " means that $0=x_{0}<x_{1}<\cdots<x_{n}=1+h_{n}$ be the Ordered Design variables.

c) In Section 3, p. 458, the sentence before equation (1) should read: Let $\mathcal{K}_{p, s}$ be the class of all real valued, bounded and continuous on $(0,1)$ functions $K=K_{p, s}$, vanishing outside of $(0,1)$ and such that.

d) In Section 3, p. 458, the first line of the Theorem 3.1 should read: If $\left\||| g^{(s)}\right\|||<\infty$, and

e) In Section 3, equation (5), the upper limit of the second integral should read: $\left(x_{n}-x\right) / h_{n}$.

f) In Section 3, p. 459, line 2, the term $\left\|g^{(1)}\right\|$ should read: $\left\|\mid g^{(1)}\right\| \|$.

g) In Section 3, p. 459, lines 3 and 4, disregard the sentence: Due to the compactness ... large.

h) In Section 3, p. 459 , line 8 , the term $\left\|g^{(s)}\right\|$ should read: $\left\|g^{(s)}\right\| \|$. 